\title{
Chart Abstraction
}

National Cancer Institute

\section{Source}

National Cancer Institute. Chart Abstraction. NCI Thesaurus. Code C113748.

The process of reading the record of a health encounter to determine and document the condition the patient had, the cause, and the treatment prescribed. This information is typically assigned standard clinical terminology codes. 